\title{
RITUXIMAB AS A SECOND LINE TREATMENT IN TWO CASES OF AUTOIMMUNE ANTI-NMDAR POST-HERPES SIMPLEX ENCEPHALITIS
}

David Torres-Fernández ${ }^{1}$, Paula Carrascosa García², Lidia Oviedo Melgares, Maria Concepción Miranda Herrero², Danie Blázquez Gamero ${ }^{1}$, Elena Rincón López ${ }^{2}$, Luis Manuel Prieto Tato ${ }^{1}$, Mar Santos Sebastián ${ }^{2}$, Pablo Rojo Conejo ${ }^{1}$, Estíbaliz Barredo Valderrama ${ }^{2}$, Cinta Moraleda Redecilla ${ }^{1}$, Juan José Carballo Belloso ${ }^{2}$, Cristina Epalza ${ }^{1}$, Elisa Fernández Cooke ${ }^{1}$

INTRODUCTION Herpes Simplex Virus (HSV) is the first cause of severe encephalitis in children. Anti-NMDAr Encephalitis is a rare complication of this condition.

\section{CASE REPORT}

We present 2 boys, 12 (patient 1) and 3 months old (patient 2) respectively that presented to $A \& E$ with fever, decreased consciousness and complex partial seizures.

MRI showed temporal lobe injuries compatible with herpetic meningoencephalitis and HSV-1 PCR in CSF was positive
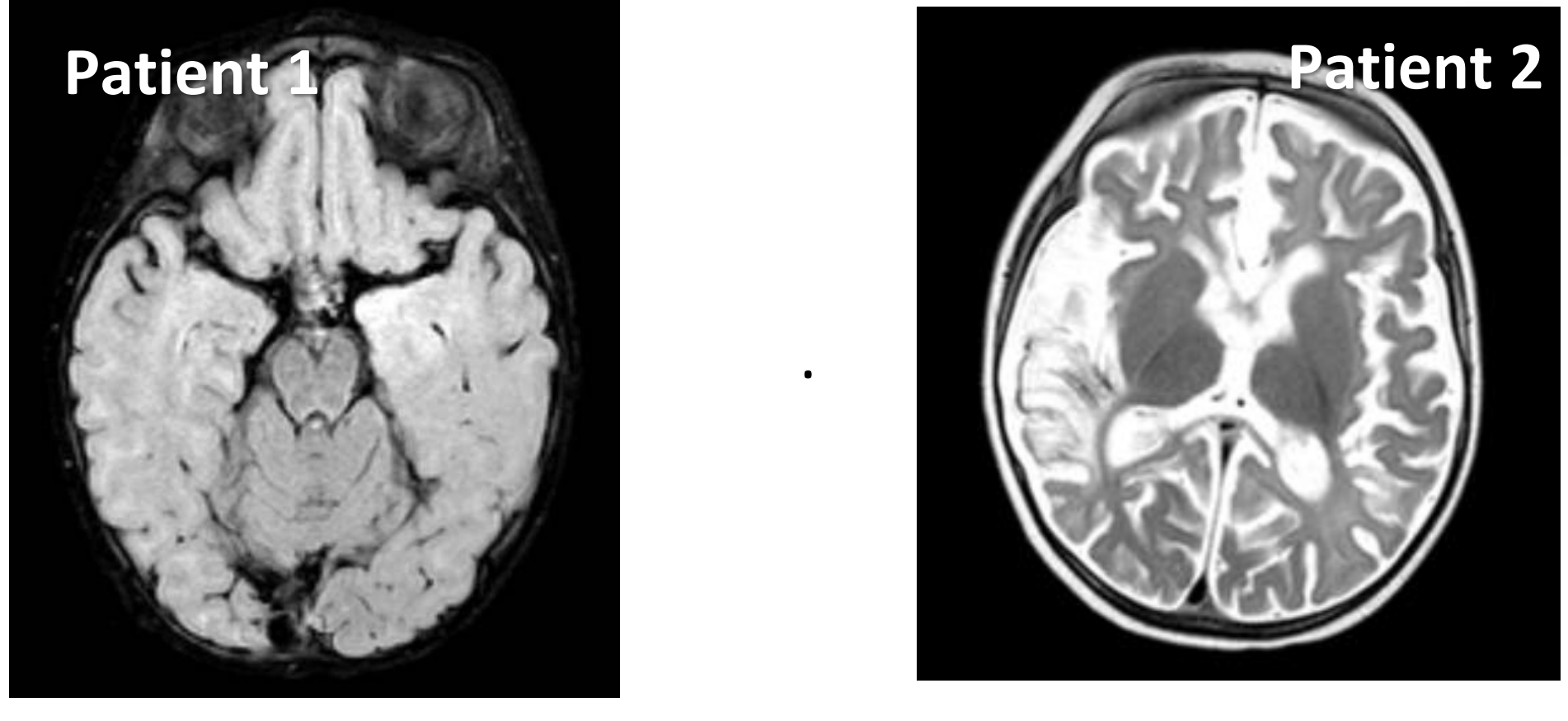

They had an initial satisfactory evolution on acyclovir and antiepileptic drugs.

After 14 and 25 days of treatment respectively, both presented sudden deterioration, with new seizures, loss of developmental milestones and appearance of choreoathetosic movements.

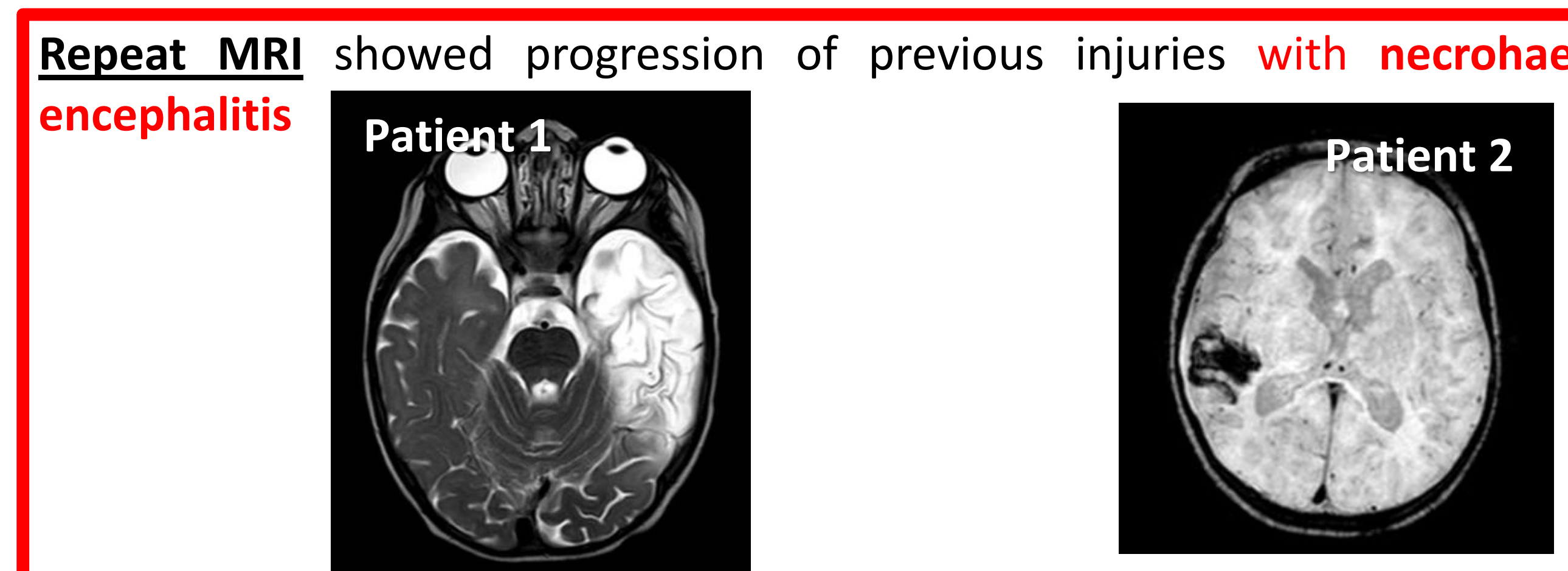

Autoimmune encephalitis was suspected, and then confirmed by presence of antibodies against brain glutamate NMDA receptor in CSF and blood serum.

Both patients received methylprednisolone during 5 days, 2 doses of Immunoglobulins, and 5 cycles of plasmafiltration. No clinical improvement was observed.

RITUXIMAB was started with 4 weekly doses, showing neurological improvement and decrease in chorea after the second dose.

7 months after treatment, patient 1 showed increasing aggressiveness and sleep disturbances as IgG anti-NMDAr rose in blood serum. Suspecting a relapse, a new cycle of Rituximab was administered with subsequent improvement and negativity of antibodies.

\section{CONCLUSION}

- Autoimmune encephalitis should be suspected if clinical worsening is observed during evolution of herpetic encephalitis and anti-NMDAr antibodies in CSF and blood serum performed.

- Treatment with Rituximab be considered early as second line treatment. 